mitindo a aplicação de resina composta fluida e a sua completa estabilização e polimerização. Discussão e conclusões: O clínico depara-se frequentemente com a dificuldade de selar eficientemente a abertura da câmara pulpar após introdução do gel, uma vez que a resina composta não polimeriza na presença de fluídos aquosos, comprometendo amplamente o sucesso do tratamento, caso a câmara pulpar não se encontre completamente selada. A criação desta barreira permitiu a aplicação correta e eficaz do protocolo de branqueamento interno, e poderá ser considerada como uma inovação a replicar futuramente neste procedimento. Ressalva-se que a colocação do referido plug não influência o resultado final do branqueamento interno.

http://doi.org/10.24873/j.rpemd.2019.12.509

\#047 Técnica restauradora semi-direta em dentes do setor posterior: Relato de um caso clínico

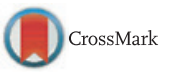

Jennifer Cardoso*, Paulo de Araújo, Sandra Gavinha, Patrícia Manarte-Monteiro, Alexandrine Carvalho, Hélder Oliveira

Universidade Fernando Pessoa

Introdução: Em situações de cáries profundas ou de fraturas coronárias com margens subgengivais, a cirurgia de alongamento coronário pode estar indicada, de forma a restabelecer os tecidos supracrestais e permitir uma maior estrutura dentária para suportar futuras restaurações. A técnica restauradora semi-direta a compósito surgiu na tentativa de colmatar as falhas inerentes às restaurações diretas e de reduzir o custo e número de consultas em relação à técnica indireta. Descrição do caso clínico: Paciente do sexo masculino, 24 anos, saudável, compareceu nas clínicas pedagógicas de medicina dentária da UFP, descontente com uma restauração antiga no dente 36 e com queixa de sensibilidade ao frio no mesmo. Ao exame clínico e radiográfico observou-se a presença de uma restauração desadaptada e infiltrada por cárie, com margens sub-gengivais, mas justa óssea. Foi proposto ao paciente uma cirurgia de alongamento coronário e a substituição da restauração antiga por um overlay de resina composta, confecionado por meio de uma técnica semi-directa. Após completa cicatrização dos tecidos periodontais, o procedimento restaurador teve início com a remoção de toda restauração antiga, seguida da confecção de um build up em resina composta, regularização das paredes e da geometria do preparo cavitário. Posteriormente ao selamento dentinário imediato, foram realizadas impressões em alginato de ambas as arcadas. Os modelos obtidos a partir do silicone e gesso foram montados em articular semi-ajustável para que a restauração fosse esculpida pela técnica incremental, respeitando a oclusão do paciente. Concluída a confecção, o polimento e a limpeza da incrustação, a mesma foi cimentada através de uma resina aquecida. Discussão e conclusões: Esta técnica restauradora é uma alternativa eficaz e de fácil execução na restauração de amplas cavidades de um ou vários dentes do sector posterior em relação às técnicas convencionais, sendo capaz de oferecer estética e função com longevidade. Além disso, consegue reunir vantagens das técnicas direta e indireta, e superar algumas desvantagens das mesmas, como: menor contração de polimerização; anatomia oclusal mais perfeita; melhores pontos de contacto obtidos na troquelização do silicone; reduzida necessidade de desgastes oclusais devido à montagem prévia dos modelos em articulador; preparos dentários mais conservadores com paredes menos divergentes; ausência de restauração provisória; menor custo e apenas uma consulta.

http://doi.org/10.24873/j.rpemd.2019.12.510

\section{\#048 Reabilitação Oral de paciente com desgaste dentário por atrição com próteses removíveis}

Rita Palos Alves*, Ricado Lourenço Rodrigues, Sónia Fangaia, Pedro Nicolau

Faculdade de Medicina da Universidade de Coimbra

Introdução: A reabilitação de pacientes bruxómanos com perda de dimensão vertical de oclusão devido a desgaste dentário, passa frequentemente por soluções fixas. No entanto, outras possibilidades deverão ser consideradas tendo em conta a especificidade de cada caso. Fatores económicos, requisitos estéticos, idade e estado de saúde geral deverão ser avaliados de forma a conseguir-se o tratamento que melhor responderá às necessidades de cada paciente. Assim, a prótese parcial removível poderá ser uma opção vantajosa para este tipo de reabilitações, quer a nível do tratamento transitório, quer definitivo. Descrição do caso clínico: Paciente de 75 anos, sexo feminino, com queixas de desconforto na utilização das suas próteses removíveis. No exame extra-oral, entre outras assimetrias a paciente apresentava uma linha de sorriso invertida. No exame intra-oral, observou-se uma Classe III de Kennedy maxilar e Classe I mandibular, desgaste dentário generalizado e acentuado, com curvas de Spee invertidas. Sem queixas de dor musculares ou articulares sugestivas de disfunção da articulação temporomandibular. Apresentava diminuição da dimensão vertical de oclusão. Considerando-se a idade, situação sistémica e disponibilidade financeira, optou-se por uma nova reabilitação protética removível. Antes do tratamento definitivo, planeou-se o tratamento transitório para restabelecimento da dimensão vertical de oclusão. Após impressões, montagem em articulador com a dimensão de oclusão vertical adequada e enceramento de diagnóstico, procedeu-se à reconstrução anatómica dos dentes protéticos com recurso a uma resina acrílica (TAB $2000^{\circledR}$ ) e da dentição natural através de restaurações diretas em resina composta e ferulização do $5 .^{\circ}$ sextante com recurso a fibra de vidro. Discussão e conclusões: A obtenção de uma posição intermaxilar fisiológica para pacientes que perderam a dimensão vertical é essencial para uma correta reabilitação protética. É importante um bom planeamento para o seu restabelecimento antes de qualquer procedimento definitivo, sendo fundamental uma fase transitória neste tipo de tratamentos. A alteração planeada de próteses removíveis pré-existentes é útil na fase transitória, para restabelecimento e adaptação da nova relação intermaxilar, que seja reprodutível no tratamento definitivo, tendo em vista um melhor prognóstico da reabilitação pretendida.

http://doi.org/10.24873/j.rpemd.2019.12.511 